\begin{tabular}{|c|c|c|}
\hline \multirow{2}{*}{$\begin{array}{r}\text { Case Reports in } \\
\text { Gastroenterology }\end{array}$} & \multicolumn{2}{|c|}{ Case Rep Gastroenterol 2016;10:36-43 } \\
\hline & $\begin{array}{l}\text { DOI: 10.1159/000442972 } \\
\text { Publisnea onme: 1Viay 19, } 2016\end{array}$ & $\begin{array}{l}\text { ( } 2016 \text { The Author(s) } \\
\text { Published by S. Karger AG, Base } \\
\text { www.karger.com/crg }\end{array}$ \\
\hline
\end{tabular}

\title{
Acute Cytomegalovirus Hepatitis in an Immunocompetent Host as a Reason for Upper Right Abdominal Pain
}

\author{
Kai Oliver Jensen ${ }^{a} \quad$ Eliane Angst ${ }^{a, c}$ Franc Heinrich Hetzer ${ }^{a}$ \\ Christian Gingert ${ }^{a, b}$ \\ ${ }^{a}$ Clinic of Surgery and Orthopedics, Cantonal Hospital Schaffhausen, \\ Schaffhausen, Switzerland; ${ }^{b}$ Faculty of Health Sciences, Department of Medicine, \\ University of Witten/Herdecke, Witten, Germany; ${ }^{\mathrm{C}}$ Department of Visceral Surgery and \\ Medicine, Inselspital, University of Bern, Bern, Switzerland
}

\section{Keywords}

Cholecystolithiasis · Cytomegalovirus - Hepatitis - Upper abdominal pain - Differential diagnosis

\begin{abstract}
Cytomegalovirus infections are widely distributed with a seroprevalence of up to $100 \%$. The majority of the cases take a silent course or deal with unspecific clinical symptoms. Complications in immunocompetent patients are rare but may affect the liver and lead up to an acute organ failure. In this case report, we describe a 35-year-old immunocompetent female with an acute cytomegalovirus infection presenting as acute hepatitis with ongoing upper right abdominal pain after cholecystectomy. Upper right abdominal pain is a common symptom with a wide range of differential diagnoses. If common reasons can be excluded, we want to sensitize for cytomegalovirus infection as a minor differential diagnosis even in immunocompetent patients.

(C) 2016 The Author(s)

Published by S. Karger AG, Basel
\end{abstract}




\section{Case Reports in \\ Gastroenterology}

Case Rep Gastroenterol 2016;10:36-43

\begin{tabular}{|l|l|}
\hline $10.1159 / 000442972$ & ( 2016 The Author(s). Published by S. Karger AG, Basel \\
\hline
\end{tabular} www.karger.com/crg

Jensen et al: Acute Cytomegalovirus Hepatitis in an Immunocompetent Host as a Reason for Upper Right Abdominal Pain

\section{Background}

Cytomegalovirus (CMV) infections have a worldwide impact due to the high congenital infection rates, disease burden and associated costs. More accurately, this virus is called the human herpesvirus type 5 . It has a seroprevalence of $30-100 \%$ depending on the age, ethnicity as well as social and immune status of the study group [1-3]. Transmission occurs via secretions like tears, saliva, urine, genital secretions, breast milk or blood. The incubation time is 4-6 weeks. Afterwards, the virus may remain clinically silent or appear with unspecific symptoms like fatigue, cough or fever in immunocompetent patients [4]. By contrast, infections may result in severe disease and failure of several organs in patients with a congenital or acquired immunodeficiency, e.g. due to HIV, the infantile immune system of newborns or under immunosuppressive therapy. The drugs of choice for treatment of CMV infections in immunosuppressed hosts are ganciclovir and valganciclovir for a less severe disease [5]. Upper right abdominal pain is one of the major symptoms when the liver is affected and is associated with elevated liver enzymes [4]. The severity may vary from mild elevated enzymes to acute liver failure [6]. In this case report, we present the case of a female patient with upper right abdominal pain and gallstones. After a cholecystectomy she had no pain relief, leading to an extensive investigation cascade resulting in this rare diagnosis.

\section{Case Presentation}

A 35-year-old obese female patient of Eritrean origin presented as an outpatient with epigastralgia and vomiting for 2 months. An ultrasound of the abdomen showed gallstones without a sign for inflammation. Therefore, she was scheduled for laparoscopic cholecystectomy. Her previous history showed lower back pain and a gluteal lipoma. The surgical procedure was performed without complications. The histological workup showed a gall bladder with signs of cholesteatosis. The patient was discharged on the second postoperative day.

One week later she presented to the emergency department with ongoing pain in the upper right abdomen. The postoperative ultrasound was normal, and we found slightly elevated liver enzymes with alanine transaminase (ALT) $101 \mathrm{U} / \mathrm{l}$, aspartate transaminase (AST) $123 \mathrm{U} / \mathrm{l}$ and gamma-glutamyl transpeptidase (GGT) $128 \mathrm{U} / \mathrm{l}$. She was prescribed pain medication and was scheduled for a follow-up visit the next day. The laboratory test of the next day showed a strong increase of the liver enzymes with ALT 1,521 U/l, AST 1,336 U/l and GGT $618 \mathrm{U} / \mathrm{l}$ (fig. 1). She complained of undiminished pain in spite of pain medication. In order to look for an abscess or an acute ischemia of the liver, the patient was hospitalized and a computed tomography (CT) of the abdomen was performed. After inconspicuous results of the CT, a magnetic resonance Cholangiopancreatography was performed addressing the question of pathology of the biliary duct system. It did not show any pathological result. With the working diagnosis of a cholangitis with increasing liver enzymes, infectious parameters with C-reactive protein (CRP) $267 \mathrm{mg} / \mathrm{l}$ and leucocytes (LC) $15 \times 10^{9} / \mathrm{l}$ at their maximum and impaired coagulation with a spontaneous international normalized ratio of 1.2 (fig. 1, fig. 2, fig. 3), antibiotic therapy with amoxicillin/clavulanic acid was initiated. In absence of a clinical improvement and a further increase of the liver enzymes, a hepatitis serology was performed and showed seropositivity for a former hepatitis type A. The simultaneously performed screening for EBV, HIV and CMV showed a former infection of EBV and an acute infection of CMV. An antiviral medication was omitted due to its toxicity, and antibiotic thera- 


\section{Case Reports in Gastroenterology}

Case Rep Gastroenterol 2016;10:36-43

(c) 2016 The Author(s). Published by S. Karger AG, Basel www.karger.com/crg

Jensen et al.: Acute Cytomegalovirus Hepatitis in an Immunocompetent Host as a Reason for Upper Right Abdominal Pain

py was terminated. With clinical and laboratory recovery (CRP $51 \mathrm{mg} / \mathrm{l}$; LC $8.1 \times 10^{9} / \mathrm{l}$; AST $29 \mathrm{U} / \mathrm{l}$ ), the patient could be discharged on day 9 of the second in-patient stay.

\section{Discussion}

In this immunocompetent patient, we diagnosed an acute CMV infection with hepatitis by immunoassay testing. Following the guidelines, we did not install an antiviral therapy, which was not indicated in our case. In a patient presenting with highly elevated liver enzymes and parameters of cholestasis but without elevated bilirubin, one must think of hepatitis.

Any patient with the appropriate risk profile should be tested for hepatitis A, B and C. If these serological tests do not confirm acute hepatitis, further serological profiles including HIV, EBV and CMV should be included. Retrospectively, the upper abdominal pain in our patient may have been based on the acute CMV infection and not due to the gallstones shown in the radiologic diagnostics. But at that time, the liver enzymes were not elevated, and symptomatic gallstones are very common and serological testing is time-consuming and expensive. Therefore, the cholecystectomy is still indicated, although in this case, the surgery may have aggravated the CMV infection. Postoperatively, surgical complications must be ruled out because they are more common in this setting.

$\mathrm{CMV}$ is the most common reason for a congenital infection worldwide. It is also presumed to be a major cause of mortality in immunocompromised patients [5]. The gold standard to confirm the diagnosis is the presence of CMV-specific antibodies type IgG and IgM in the (maternal) blood sample running an immunoassay or a polymerase chain reaction, which can be either qualitative or quantitative by measuring the amount of viral DNA in the respective sample[4, 5]. CMV disease typically presents as mild and self-limiting mononucleosis syndrome without an organ complication [3]. Therefore, in immunocompetent individuals no treatment is needed. CMV diseases are more often complicated in HIVpositive or other immunocompromised patients like those with organ transplantation, bone marrow transplantation, neutropenia due to chemotherapy or radiation therapy. Complications might manifest as retinitis, esophagitis, and enteritis. Other manifestations include peripheral neuropathy, polyradiculoneuritis, pneumonitis, gastritis, colitis, and hepatitis [5]. Hepatitis as a manifestation of CMV infection is a rare but known complication usually not needing antiviral therapy due to its self-limiting course. Antiviral treatment is reserved for severe CMV infections because of its potential side effects including myelosuppression, central nervous system disorders, hepatotoxicity, irreversible infertility (inhibition of spermatogenesis), or teratogenesis [7]. Indications for antiviral treatment are mostly based on the clinical course and on the polymerase chain reaction threshold. The cutoff varies from institution to institution but in general it is located around 10,000 viral copies $/ \mathrm{ml}$ of blood [5]. When treatment is needed, it should be given for a minimum of 2-3 weeks. The end point of intravenous therapy is the documented clearance of virus from the blood. Regimens for adults should be adjusted for renal dysfunction (table 1). To avoid a relapse after intravenous therapy, oral treatment with valganciclovir for 2-3 months may be performed in highrisk patients (table 2) [8, 9]. 
Jensen et al.: Acute Cytomegalovirus Hepatitis in an Immunocompetent Host as a Reason for Upper Right Abdominal Pain

\section{Conclusions}

With this case report, we want to raise the awareness for an unusual diagnosis: an acute CMV infection. If common reasons for upper right abdominal pain are ruled out, clinical symptoms are persistent, and liver enzymes are elevated, this diagnosis should be sought, regardless whether patients are immunocompetent or not.

\section{Statement of Ethics}

Written informed consent was obtained from the patient for publication of this case report and the accompanying tables and figures.

\section{Disclosure Statement}

The authors declare that they have no competing interests.

\section{References}

$>1$ Ludwig A, Hengel H: Epidemiological impact and disease burden of congenital cytomegalovirus infection in Europe. Euro Surveill 2009;14:26-32.

-2 Knowles SJ, Grundy K, Cahill I, Cafferkey MT, Geary M: Low cytomegalovirus sero-prevalence in Irish pregnant women. Ir Med J 2005;98:210-212.

-3 Chan A, Bazerbachi F, Hanson B, Alraies MC, Duran-Nelson A: Cytomegalovirus hepatitis and pancreatitis in the immunocompetent. Ochsner J 2014;14:295-299.

4 Revello MG, Gerna G: Diagnosis and management of human cytomegalovirus infection in the mother, fetus, and newborn infant. Clin Microbiol Rev 2002;15:680-715.

-5 Ross SA, Novak Z, Pati S, Boppana SB: Overview of the diagnosis of cytomegalovirus infection. Infect Disord Drug Targets 2011;11:466-474.

6 Silverio CE, Smithen-Romany CY, Hondal NI, Diaz HO, Castellanos MI, Sosa O: Acute liver failure in Cuban children. MEDICC Rev 2015;17:48-54.

-7 Rafailidis PI, Mourtzoukou EG, Varbobitis IC, Falagas ME: Severe cytomegalovirus infection in apparently immunocompetent patients: a systematic review. Virol J 2008;5:47.

8 Fishman JA: Guidelines for therapy of cytomegalovirus infection. Transplant Infectious Disease and Compromised Host Program XII.

-9 Kotton CN, Kumar D, Caliendo AM, Asberg A, Chou S, Snydman DR, Allen U, Humar A: International consensus guidelines on the management of cytomegalovirus in solid organ transplantation. Transplantation 2010;89:779-795. 

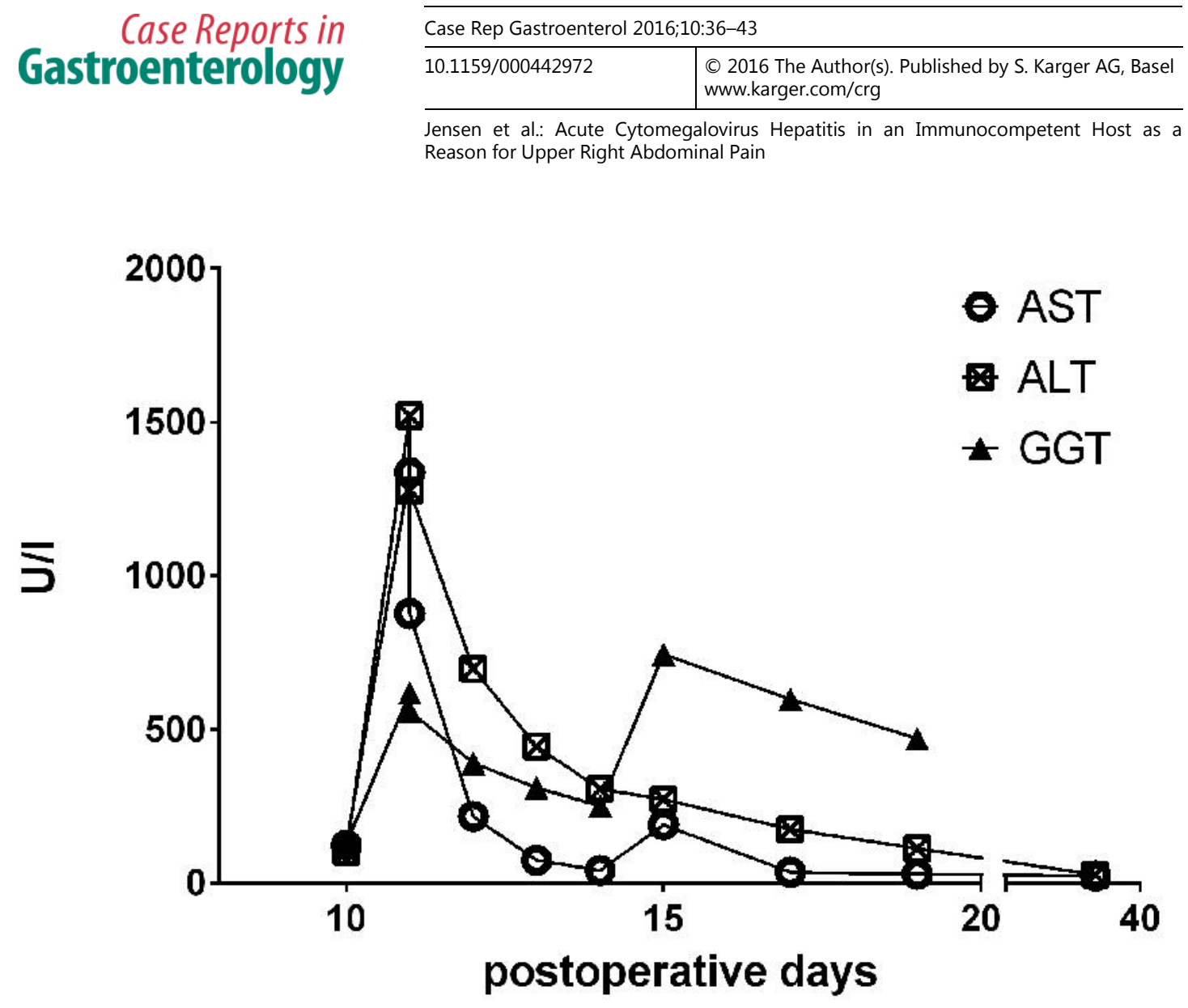

Fig. 1. Chronological trend of liver enzymes during the postoperative course. 

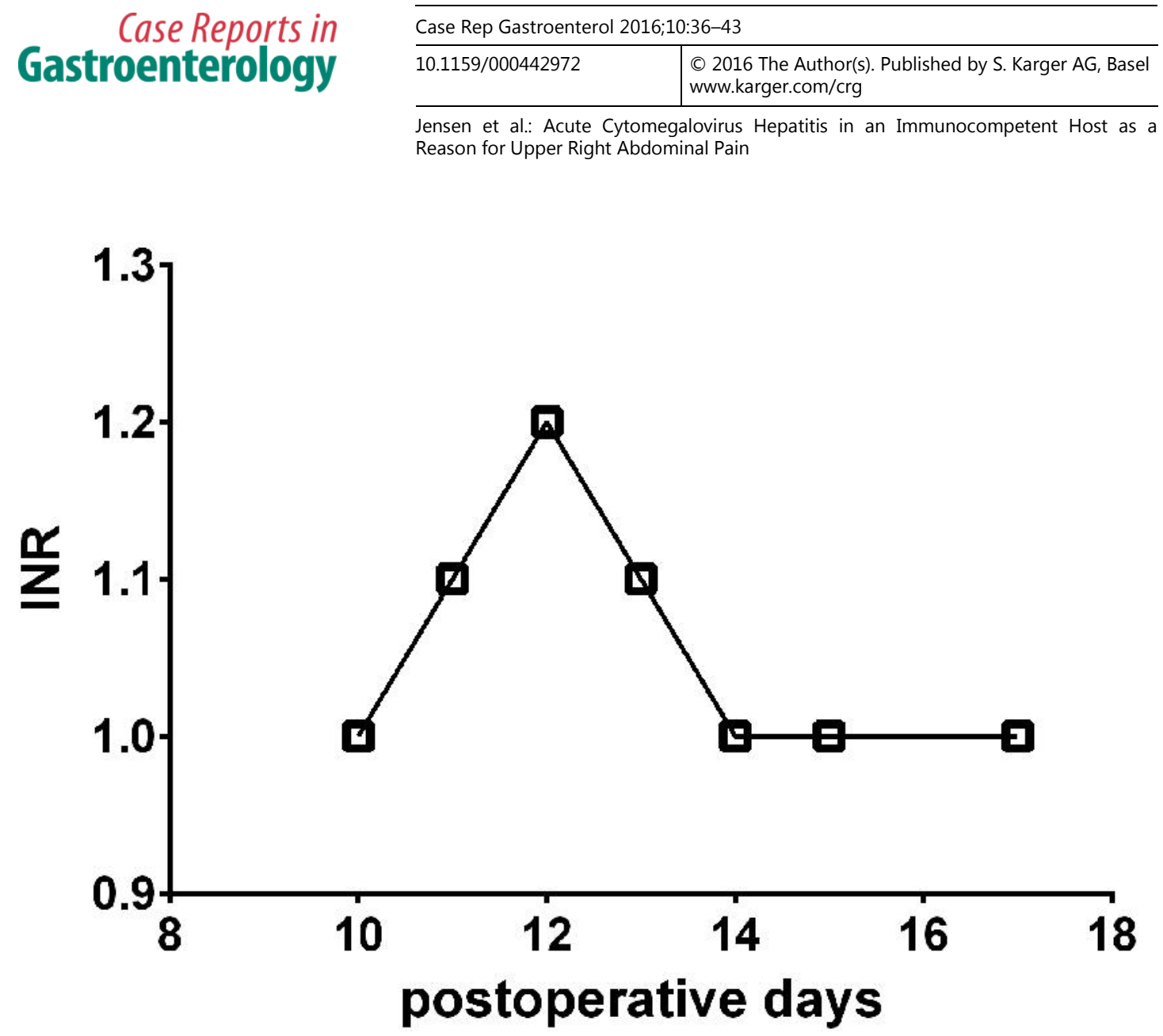

Fig. 2. Chronological trend of coagulation measured by international normalized ratio (INR) during the postoperative course. 


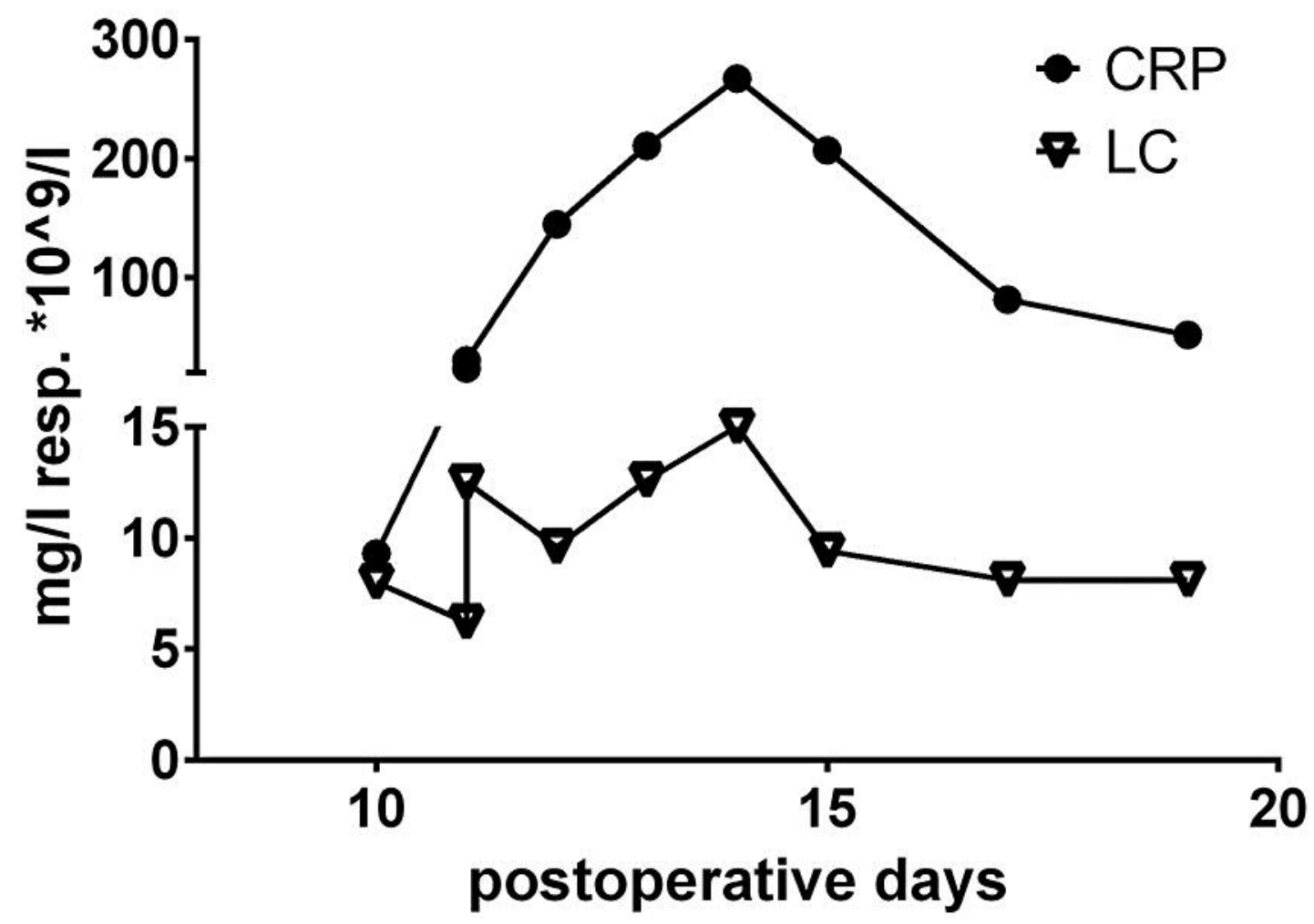

Fig. 3. Chronological trend of infectious parameters given as CRP and LC during the postoperative course.

Table 1. Dosing of intravenous ganciclovir for the treatment of CMV infection including dose modification for patients with impaired renal function [8]

\begin{tabular}{cll}
\hline & $\begin{array}{l}\text { Intravenous dose, } \\
\mathrm{mg} / \mathrm{kg}\end{array}$ & Frequency \\
\hline $\begin{array}{c}\text { Serum creatinine } \\
<2.0 \mathrm{mg} / \mathrm{dl}\end{array}$ & 5 & \\
$2-3 \mathrm{mg} / \mathrm{dl}$ & 5 & Q12h \\
$3-5 \mathrm{mg} / \mathrm{dl}$ & 1.25 & Daily \\
$>5.0 \mathrm{mg} / \mathrm{dl}$ & $1.25^{\mathrm{a}}$ & Daily \\
Hemodialysis & 5 & QOD \\
Peritoneal dialysis & $2.5^{\mathrm{a}}$ & Post-dialysis \\
\hline
\end{tabular}

Q12h = Every $12 \mathrm{~h}$; QOD = every other day.

a After a loading dose of $5 \mathrm{mg} / \mathrm{kg}$ i.v. 
Jensen et al.: Acute Cytomegalovirus Hepatitis in an Immunocompetent Host as a Reason for Upper Right Abdominal Pain

Table 2. Dosing of oral valganciclovir for the treatment of CMV infection including dose modification for patients with impaired renal function [8]

\begin{tabular}{lll}
\hline & Treatment dose, mg & Frequency \\
\hline $\begin{array}{c}\text { Serum creatinine } \\
\leq 1.5 \mathrm{mg} / \mathrm{dl}\end{array}$ & 900 & \\
$1.6-2.5 \mathrm{mg} / \mathrm{dl}$ & 450 & BID \\
$2.6-4.0 \mathrm{mg} / \mathrm{dl}$ & 450 & BID \\
$>4.0 \mathrm{mg} / \mathrm{dl}$ & 450 & QD \\
Hemodialysis & unknown & QOD \\
Peritoneal dialysis & unknown & unknown \\
\hline
\end{tabular}

$\mathrm{BID}=$ Twice a day; $\mathrm{QD}=$ every day; $\mathrm{QOD}=$ every other day. 